\title{
A 12-pulse rectifier using coupled reactors for supplying three-inverters
}

\author{
J. Iwaszkiewicz ${ }^{1}$, A. Muc ${ }^{1}$ and P. Mysiak ${ }^{1}$ \\ ${ }^{1}$ Department of Electrical Engineering \\ Gdynia Maritime University, Poland \\ Morska St. 81-87 (Poland) \\ e-mail: j.iwaszkiewicz@we.umg.edu.pl, a.muc@we.umg.edu.pl, p.mysiak@we.umg.edu.pl
}

\begin{abstract}
The paper presents a proposal of an auspicious multi-pulse rectifier convenient for supplying three-level inverters. The rectifier consists of two three-phase bridges. Their outputs are connected in parallelwhile inputs are connected to the line by use of coupled reactors These reactors are connected and work in an exceptional variant $3 \mathrm{CR} \lambda$. The application of $3 \mathrm{CR} \lambda$ makes that the diodes conduction angle in rectifiers achieves $180^{\circ}$. Simulation and experimental works prove that multi-pulse rectifier gives a worthy performance and has some respectable properties.
\end{abstract}

\section{Key words}

Multi-pulse rectifier, 12 pulse rectifier, coupled reactors, 3-level inverter

\section{Introduction}

Providing supply for electrical energy conversion systems in which multilevel inverters are used brings serious problems related with the load of the supply network. On the one hand, contemporary converters are designed using very fast switching semiconductor connectors, which reduces their electromagnetic compatibility. On the other hand, those systems are used in situations when large power is required at the reception side $[1,2,3]$.

A multilevel voltage inverter requires a multipolar DC voltage supply in which the number of poles corresponds to the number of levels in the inverter. For instance, in the three-level voltage inverter of NPC type, the internal inverter system should be capable of being connected to three poles of the supply network. In standard NPC inverters, a common procedure is to use for this purpose an intermediate circuit with divided voltage $U_{D}$, the three poles of which correspond to potentials $0, \mathrm{U}_{\mathrm{D}} / 2$, and $\mathrm{U}_{\mathrm{D}}$. The voltage to the intermediate circuit is usually delivered by the rectifiers, which are AC/DC voltage converters. The rectifiers, along with the intermediate circuit and the inverter working, for instance, in drives with AC motors, are nonlinear receivers of electrical energy which generate higher harmonics in the supply network. These harmonics are highly undesirable, since they are a source of additional power losses in the supply line, deform the supply voltage, and emit electromagnetic signals which disturb the operation of IT and control systems. The international standards, IEEE for instance, define very severe requirements concerning the presence of higher harmonics in the currents taken from the supply sources and the permissible voltage distortion [4]. The main current and voltage distortion coefficients are defined as follows:

$$
T H D_{I}=\frac{\sqrt{\sum_{h=2}^{\infty} I_{h}^{2}}}{I_{1}} \cdot 100 \%=\frac{\sqrt{I^{2}-I_{1}^{2}}}{I_{1}} \cdot 100 \%
$$

where $\mathrm{h}$ is the order of the harmonic, $\mathrm{I}_{\mathrm{h}}$ is the RMS value of the current harmonic, $I_{1}$ is the RMS value of the fundamental current harmonic and I is the RMS value of the current taken from the supply source. Similarly, the Total Harmonic Distortion of the voltage, $\mathrm{THD}_{\mathrm{U}}$, is defined as:

$$
T H D_{U}=\frac{\sqrt{\sum_{h=2}^{\infty} U_{h}^{2}}}{U_{1}} \cdot 100 \%=\frac{X_{Z}}{U_{1}} \sqrt{\sum_{h=2}^{\infty}\left(h \cdot I_{h}\right)^{2}} \cdot 100 \%
$$

because $U_{h}=h X_{Z} I_{h}$. Here, $\mathrm{X}_{\mathrm{z}}$ is the supply source reactance, which is determined from the short-circuit test. Once the short-circuit current $I_{z}$ is known, the reactance can be calculated as $X_{z}=U_{1} / I_{z}$.

The permissible voltage distortion coefficient for receivers supplied from the LV network is equal to $3 \%$ in the case of special objects, such as hospitals or airports for instance, and to $5 \%$ for general objects, industrial plants for instance. It results that, in general, the permissible current distortion coefficient should not exceed several percent $(2 \% \div 10 \%)$. It is also noteworthy here that the requirements referring to permissible amplitudes of individual current harmonics are also standardised.

A multi-pulse AC/DC converter generates current harmonics, the order of which depends on $q$ where $q$ is the number of pulses in one period of the current

$$
h=k q \pm 1 \quad k \in \mathrm{N}
$$

An obvious conclusion resulting from it is that we should use converter systems with large q values (multi-pulse 
systems) to meet the requirements defined by the standards. In practice, 6-, 12-, and 18-pulse systems are frequently used for electric drive purposes. The following approximate $\mathrm{THD}_{\mathrm{I}}$ values representing the contents of higher current harmonics are obtained: $31 \%$ for $q=6 ; 15 \%$ for $\mathrm{q}=12$, and $9,6 \%$ for $\mathrm{q}=18$. Certainly, increasing the supply source reactance by using reactors leads to considerable reduction of $\mathrm{THD}_{\mathrm{I}}$.

In classical solutions, the $q$ value can be multiplied, for instance, by serial or parallel connection of three-phase bridge systems and relevant phase shift in the transformers supplying the converters $[5,6]$.

This article presents a proposal of a system supplying three-level inverters where DC voltage is obtained from the AC/DC converter in which multi-pulse diode rectifiers with coupled reactors were applied to block higher current harmonics. The converter system ensures considerable reduction of the distortion factor of the current taken from the supply source $[7,8,9,10]$.

\section{Multi-pulse AC/DC converter using coupled reactors}

The schematic diagram of the 12-pulse diode rectifier in which magnetically coupled reactors were used in the variant $3 \mathrm{CR} \lambda$ is shown in Fig. 1. The rectifier consists of two three-phase bridges (P1, P2) connected in parallel, and delivers the voltage $2 \mathrm{E}_{\mathrm{d}}$ to the $\mathrm{R}-\mathrm{C}$ load. The capacitance $\mathrm{C}$ resulting from serial connection of two capacitances $2 \mathrm{C}$ makes the system act as a voltage source. Figure 1 presents too the schematic diagram of the considered rectifier supplying a 3-level NPC inverter. The operation of the system, the way of determining current and voltage waveforms, as well as the design and results of simulation and experimental tests have been presented and discussed in $[5,6,7,8]$.

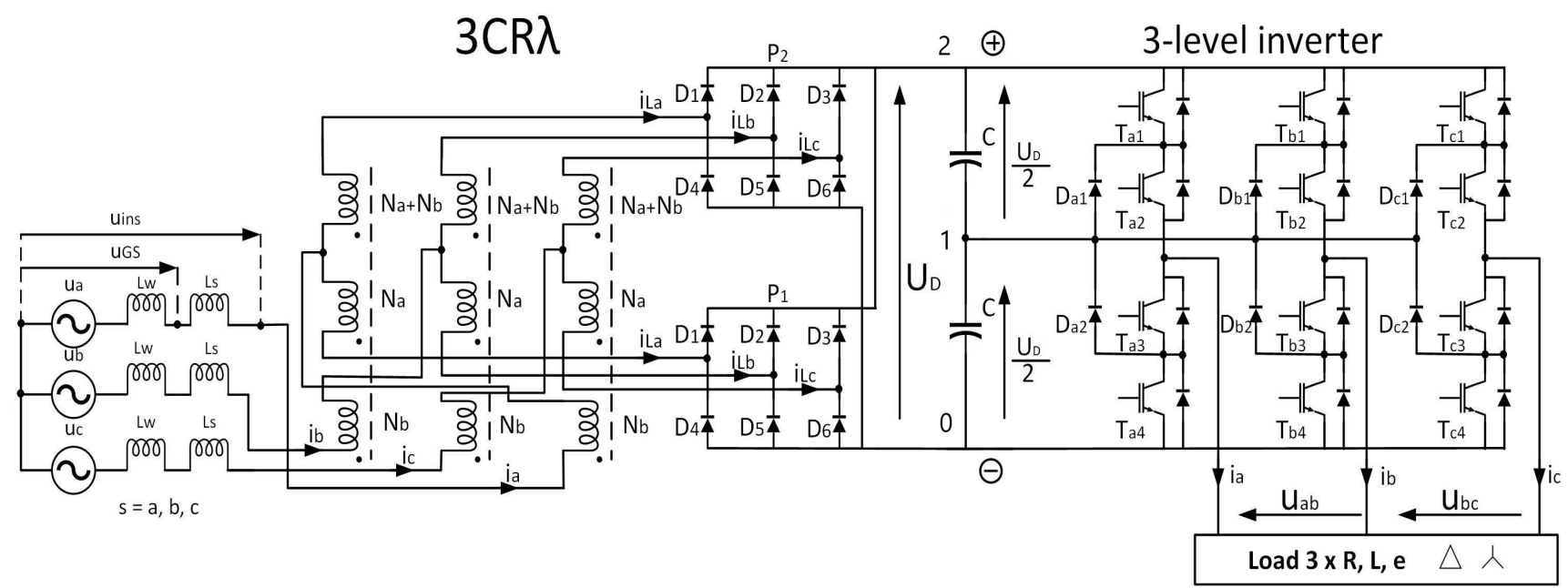

Fig. 1. Schematic diagram of the considered rectifier supplying a 3-level inverter.

The essence of operation of coupled reactors consists in blocking (eliminating) higher harmonics, of the order of $6 \mathrm{k} \pm 1$, in the output voltage. The application of $3 \mathrm{CR} \lambda$ reactors makes that the diode conduction angle in bridge rectifiers is $180^{\circ}(\pi)$, against $2 \pi / 3$ in conventional receivers acting as current sources. The reactors are constructed of three separate magnetic cores with selected numbers of turns $\left(\mathrm{N}_{\mathrm{a}}, \mathrm{N}_{\mathrm{b}}, \mathrm{N}_{\mathrm{a}}+\mathrm{N}_{\mathrm{b}}\right)$. When the turns ratio is selected properly, two symmetric three-phase voltage systems, phase shifted by $\pi / 6$, are obtained at reactor output. Since the diode conduction angle in the rectifier is equal to $\pi$, the voltage at output terminals of the reactors has the 12-pulse waveform at nominal load. The rectifier with a system of coupled reactors is supplied from the three-phase network having the internal inductance $L_{w}$ in each phase. Network reactors of inductance $L_{s}$, much higher than the internal inductance of the source, $\mathrm{L}_{\mathrm{s}} \gg \mathrm{L}_{\mathrm{w}}$, were installed between the phase voltage and the rectifier input.

\section{Simulation Tests}

The simulation tests of system operation were performed for different network reactor inductances, assuming that the load power was constant and equal to $2 \mathrm{kVA}$.
The percentage relation between $\mathrm{L}_{\mathrm{s}}$ and the short-circuit voltage of the supply source is given by the formula $\mathrm{u}_{\mathrm{z} \%}=\left(\omega \mathrm{L}_{\mathrm{s}} \mathrm{I}_{\mathrm{s}} / \sqrt{3} \mathrm{U}_{\mathrm{s}}\right) \cdot 100 \%$. Basic parameters of the simulation model of the rectifier system are collated in Table 1.

Table I. - Parameters of simulation and laboratory models of 2 $\mathrm{kVA}$ 12-pulse rectifier

\begin{tabular}{|l|l|}
\hline Nominal line-to-line voltage & $\mathrm{U}_{\mathrm{s}}=400 \mathrm{~V}$ \\
\hline Short-circuit voltage of supply source $\left(\mathrm{L}_{\mathrm{w}}+\mathrm{L}_{\mathrm{s}}\right)$ & $\mathrm{u}_{\mathrm{z} \%}=10 \%$ \\
\hline Maximal inductance in magnetic cores & $\mathrm{B}_{\mathrm{m}}=1,0 \mathrm{~T}$ \\
\hline Number of turns $\mathrm{N}_{\mathrm{a}}$ in winding & 204 \\
\hline Number of turns $\mathrm{N}_{\mathrm{b}}$ in winding & 75 \\
\hline Inductance of network reactor & $\mathrm{L}_{\mathrm{s}}=22 \mathrm{mH}$ \\
\hline Capacitance of load circuit capacitor & $\mathrm{C}=10 \mathrm{mF}$ \\
\hline Resistance of load & $\mathrm{R}=102 \Omega$ \\
\hline Current density in coupled reactor windings & $\mathrm{J}=2,5 \mathrm{~A} / \mathrm{mm}^{2}$ \\
\hline Cross section area of TDS $\lambda$ core column & $\mathrm{S}_{\mathrm{Fe}}=8 \mathrm{~cm}^{2}$ \\
\hline Shift angle of diode bridge input current vectors & $2 \alpha=30^{\circ}$ \\
\hline Internal inductance of supply line & $\mathrm{L}_{\mathrm{w}}=0,1 \mathrm{mH}$ \\
\hline Coefficient of core filling with iron & $\mathrm{k}_{\mathrm{Fe}}=0,9$ \\
\hline
\end{tabular}

Figure 2 shows the results of simulation tests in the form of the waveforms of phase currents taken from the network for different values of inductance $\mathrm{L}_{\mathrm{s}}$. 


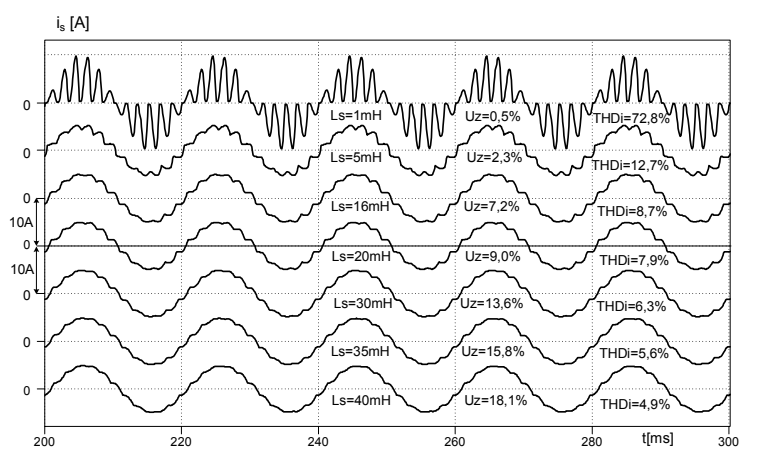

Fig. 2. Source current waveforms as functions of $\mathrm{L}_{\mathrm{s}}$ in the rectifier arrangement from Fig. 1.

The next figure, Fig. 3, presents the $\mathrm{THD}_{\mathrm{i}}$ values as functions of the short-circuit voltage and the reactor inductance $\mathrm{L}_{\mathrm{s}}$.

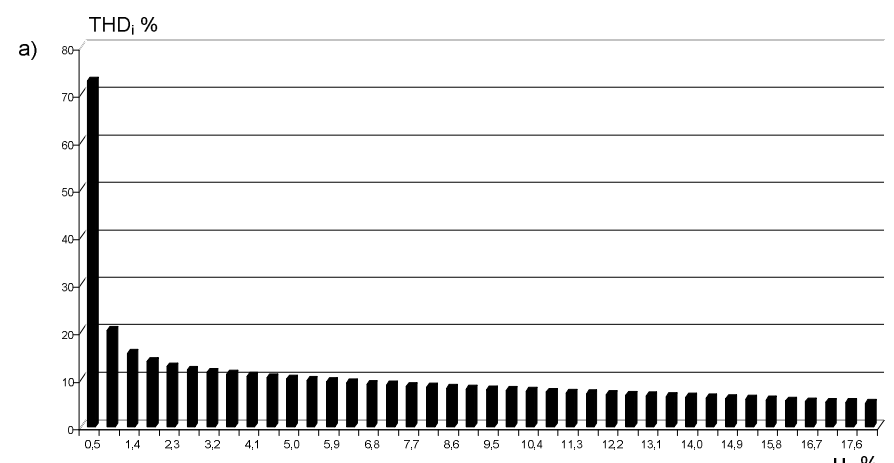

b)

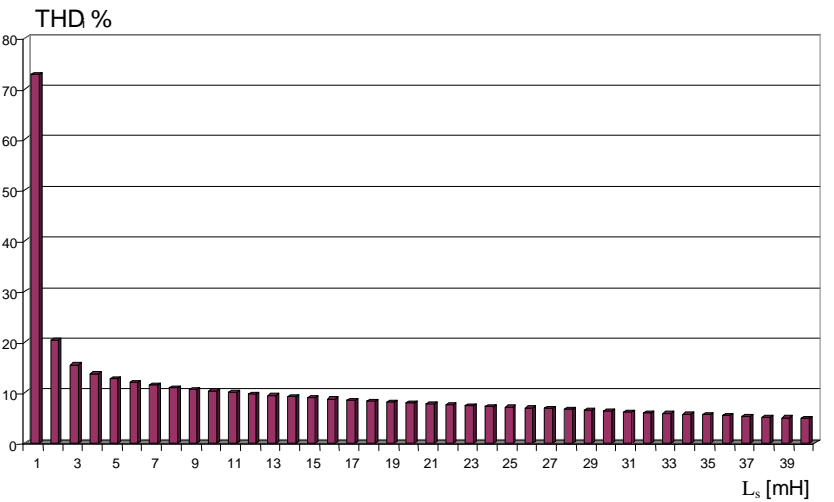

Fig. 3.THD ${ }_{\mathrm{i}}$ factor as function of: a) short-circuit voltage, b) reactor inductance $\mathrm{L}_{\mathrm{s}}$.

It was assumed that the network is symmetrical, and the phase voltage waveforms have the shape of a mathematical sine curve. For a small value of $\mathrm{L}_{\mathrm{s}}\left(1 \mathrm{mH}, \mathrm{u}_{\mathrm{z}} \%=0,5 \%\right)$, the current waveform is discontinuous and the total harmonic distortion coefficient, $\mathrm{THD}_{\mathrm{i}}$, reaches $72,7 \%$.

Increasing the inductance improves the shape of the supply current waveform. For the inductance $\mathrm{L}_{\mathrm{s}}=20 \mathrm{mH}$ and the assumed load of $2 \mathrm{~kW}$, the $\mathrm{THD}_{\mathrm{i}}$ value is below $8 \%$. Certainly, increasing the inductance $\mathrm{L}_{\mathrm{s}}$ leads to the increase of the commutation angle. $\mathrm{THD}_{\mathrm{i}}$ decreases to about $10 \%$ when the short-circuit voltage increases to $5 \%$ $\left(\mathrm{L}_{\mathrm{s}} \approx 10 \mathrm{mH}\right)$, which is the value typical for transformers of several hundred $\mathrm{kVA}$ in power. Reaching this $\mathrm{THD}_{\mathrm{i}}$ value in the 12-pulse system can be considered a good result, as the $\mathrm{THD}_{\mathrm{i}}$ value of the 12-pulse rectifier loaded with the current source is $15,2 \%$ when neglecting the current source inductance. Figure 4 presents the amplitudes of the selected higher harmonics $(\mathrm{n}=11,13,23,25,35,37)$ as a function of the current source inductance.

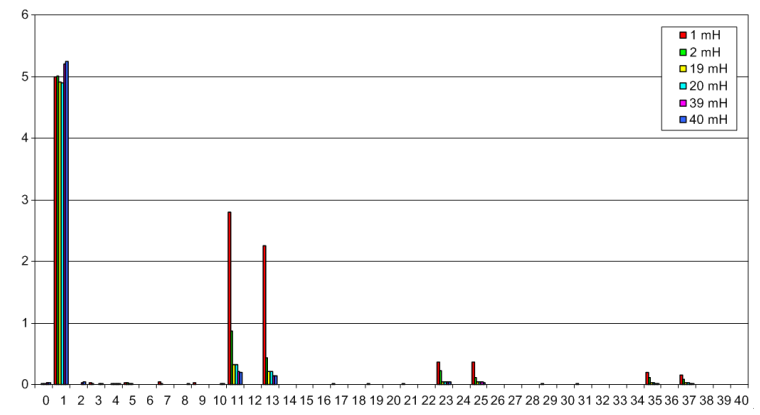

Fig. 4. Amplitudes of selected harmonics for different values of inductance $\mathrm{L}_{\mathrm{s}}$ and constant load power $2 \mathrm{kVA}$.

The obtained results have revealed that in the assumed short circuit voltage interval, the increase of inductance $\mathrm{L}_{\mathrm{s}}$ did not practically affect the amplitude of the fundamental current harmonic, but led to a considerable decrease in amplitudes of higher harmonics existing in the 12-pulse rectifier system.

\section{Experimental Results}

Should clearly indicate advantages, limitations and possible applications. Experimental tests have been executed on assumption that 3-level inverter introduced to the system the load equal to $2 \mathrm{~kW}$. It was assumed that the state of the inverter was described by a voltage vector $\mathrm{V}_{210}$ what means that phase $\mathrm{A}$ has been connected to point $2\left(\mathrm{U}_{\mathrm{D}}\right)$, phase $\mathrm{B}$ to point $1\left(\mathrm{U}_{\mathrm{D}} / 2\right)$ and phase $\mathrm{C}$ to point 0 . Next figures, Figures 5-9 illustrate results of the experimental tests done at $2 \mathrm{~kW}$ load. These tests included measurements of waveforms of the following quantities: input voltage for the $3 \mathrm{CR} \lambda$ system (Fig. 1); current taken from the supply source, and winding currents in the 3CR $\lambda$ system (Fig. 2); current taken from the supply source and the voltage measured on terminals $K_{1} K_{2}$ (Fig. 8).

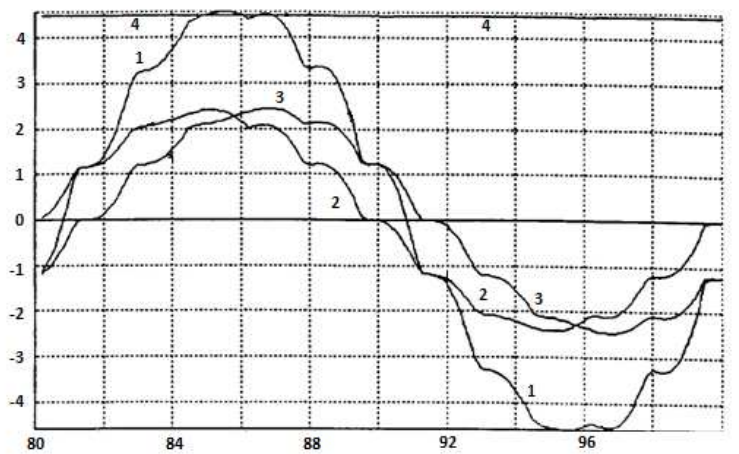

Fig. 5. Waveforms of network current $i_{R / 1 /}$, stabilised current $i_{d / 4 /}$ and $3 \mathrm{CR} \lambda$ winding currents $i_{1 R / 2 /}, i_{2 R / 3 /}$ for the $2 \mathrm{~kW}$ rectifier. 


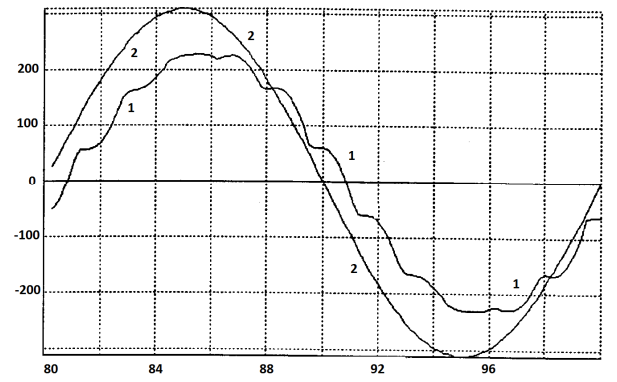

Fig. 6. Waveforms of voltage $u_{p / 2 /}$ and current $i_{R / 1 /}$ of the supply line, at nominal load of the $2 \mathrm{~kW}$ rectifier.

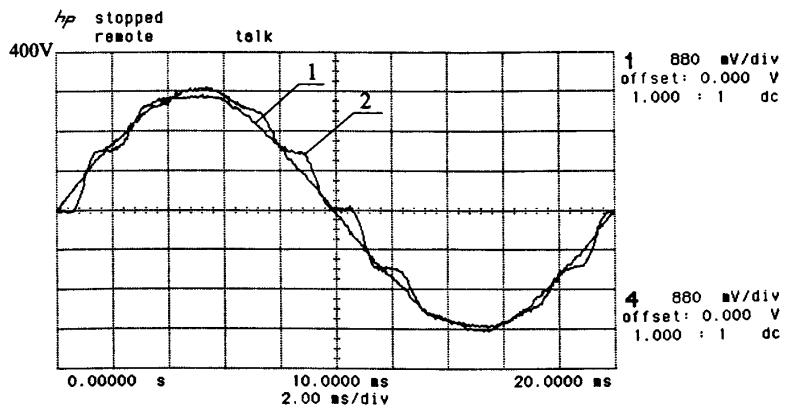

Fig. 7. Oscillograms of undistorted phase voltage $u_{R-1}$ in the supply network, and voltage $u_{G R O-2}$ at input terminals of the $3 \mathrm{CR} \lambda$ system at nominal converter load.

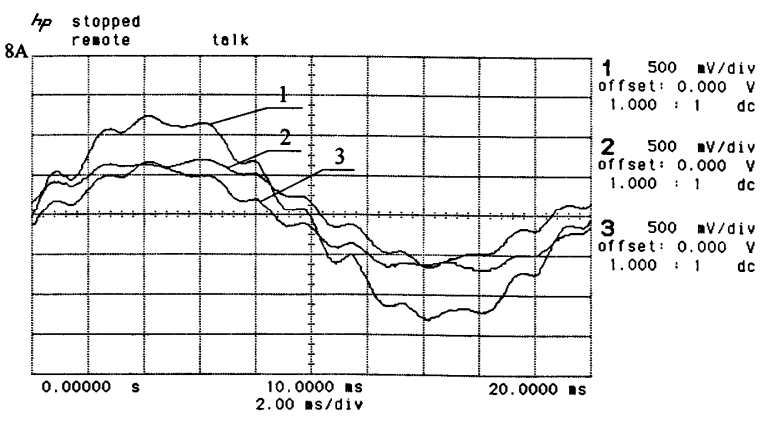

Fig. 8. Oscillograms of network current $i_{R-1}$ and 3CR $\lambda$ winding currents $i_{1 R-2}, i_{2 R-3}$ at nominal converter load.

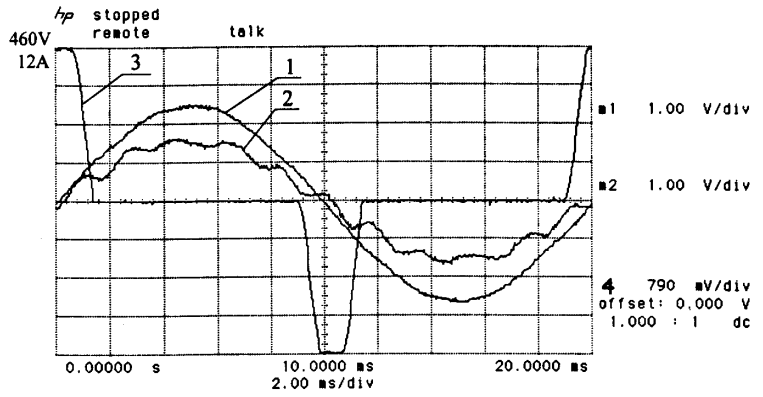

Fig. 9. Oscillograms of voltage $u_{R-1}$ and current $i_{R-2}$ in the supply line, and voltage $u_{K 1 R K 2 R-3}$ on main $3 \mathrm{CR} \lambda$ windings, at rated converter load.

The presented results of the simulation and experimental tests comply to a sufficient degree with the theoretical results.

\section{Conclusion}

The presented research work based on simulation and experimental tests proved a significant usefulness of multi-pulse rectifiersfor supplying multilevel inverters. The paper presents the 12-pulse rectifier connected to the line by use of three-phase coupled reactors. The 12-pulse rectifier consists of two classic bridge rectifiers and the reactors are connected and work in a special variant $3 \mathrm{CR} \lambda$ described in cited contributions. The application of such a solution makes that the diodes conduction angle in rectifiers achieves $180^{\circ}$. Certainly increasing the inductance improves the shape of the supply current waveform but it leads to the increase of the commutation angle. For the inductance $\mathrm{L}_{\mathrm{s}}=20 \mathrm{mH}$ and the assumed load of $2 \mathrm{~kW}$, the $\mathrm{THD}_{\mathrm{i}}$ value is below $8 \%$. Although the experimental tests have been done on low power level but these works proved that multi-pulse rectifier gives a worthy performance and has some respectable properties.

\section{References}

[1] J. Iwaszkiewicz, P. Bogusławski, A. Krahel, E. Łowiec, "Three-phase Voltage Outages Compensator with Cascaded Multilevel Converter", in Archives of Electrical Engineering, Vol. 61, No. 3, pp. 325-336.

[2] J. Iwaszkiewicz, L. Wolski, M. Perez Donsión, "A Case Study Control on High Power Compensator of the Power Grid Irregularities for Industrial Appliances", in International Conference on Renewable Energy and Power QualityICREPQ'13, Bilbao, 20-22 March 2013, Spain.

[3] J. Iwaszkiewicz, A. Muc, "A three phase 3-level inverter with reduced THD factor", in International Conference on Renewable Energy and Power QualityICREPQ'18, Salamanca, 21-23 March 2018, Spain.

[4] IEEE Std 1159-2009 (Revision of IEEE Std 1159-1995) IEEE Recommended Practice for Monitoring Electric Power Quality

[5] P. Mysiak, R. Barlik, "An DC-output twelve-pulse converter in the low voltage power network supply conditions", in International Conference on Power Electronics and Motion Control, Warsaw University of Technology, Warsaw Poland, 1994.

[6] P. Mysiak, "Multipulse Diode Converters - Frequency Doma in Analysis of Operation of the Applied Coupled Three-Phase Reactor", in $6^{\text {th }}$ International ConferenceWorkshop, Compatibility And Power Electronics (CPE 2009), Badajoz, Spain, May 20-22, 2009.

[7] P. Mysiak, "Eighteen-pulse diode rectifier with three-phase coupled reactors", in Archives of Electrical Engineering, Vol. L, No 1, Warsaw, 2001.

[8] M. Depenbrock, C. Niermann, "A New 12-Pulse Rectifier Circuit with Line-Side Interphase Transformer and Nearly Sinusoidal Line Current", in Proc. of the 6th Conference on Power Electronics and Motion Control, Budapest, Hungary, Oct. 1-3, Vol. 2, 1990, pp. 374-378.

[9] M. Depenbrock, C. Niermann, "A new 18-pulse rectifier circuit with line-side interphase transformer and nearly sinusoidal line currents", in Conf. IAS 1990.

[10] M. Depenbrock, C. Niermann, "Netzfreundliche Gleichrichterschaltung mit netzseitiger Saugdrossel (TDS) Teil II: Eigenschaften", in Etz Archiv Bd. 11 (1989) H.10, pp. 317-321. 